\title{
Inhaltsverzeichnis.
}

Solte

Vorwort . . . . . . . . . . . . . . . . . . . . V

Vorwort zum Neudruck . . . . . . . . . . . . . . . . . VIII

Erster Tell: Vor Plato

A. Anazagoras . . . . . . . . . . . . . . . . . . . . 1

B. Diogenes von Apollonia. . . . . . . . . . . . 6

I. Grundlegung . . . . . . . . . . . . . . . . . 6

1. Seine Werke. . . . . . . . . . . . . . . 6

2. Zur Nachwirkung des Diogenes . . . . . . . . . . . 7

3. Terminologie bei Nachahmern and Berichterstattern . . . 9

4. Diogenes in der Homerexegese . . . . . . . . . . 10

II. Teleologie des Diogenes . . . . . . . . . . . . . . 13

1. Fragmente . . . . . . . . . . . . . . . . . . . 13

2. Bei Xenophon . . . . . . . . . . . . . . . . . . 14

a) Allgemeines zu den teleologischen Kapiteln der Memorabilien 14

b) Beziehung von Mem. 1,48 zu Plato Phil. $28 \mathrm{~d}$ ff. . . . . 16

c) Xen. Mem. 1,417 und Diogenes . . . . . . . . . . . 19

d) Xen. Mem. 1,48 und Diogenes . . . . . . . . . . . 21

Die Argumentation bei Aristoteles $\pi .40 x .411$ a $7 \mathrm{ff} . \quad . \quad 23$

e) Xen. Men. 1,46 und Aristoteles . . . . . . . . . . . 24

Aristoteles abhangig von Diogenes . . . . . . . . . 25

Spuren von Technikvergleichen bei Diogenes . . . . . 29

f) Xen. Conv. 5 ff. und Diogenes . . . . . . . . . . . 31

g) Xen. Mem. 1,411 und Diogenes . . . . . . . . . . . 32

b) Der naturphilosophische Ontergrund von Mem. 4,318f. . . 32

3. Zusammenfassung: Notwendigkeit und Geistigkeit . . . . . 35

C. Die teleologiachen Partien bei Xenophon im ganzen and ihre Beziehung $z a$ auBernaturphilosophischen Gedanken . 36

1. Allgemeines aber die Arbeitsweise Xenophons . . . . . . . 36

2. Xen. Mem. 48 and seine drei Hanptquellen . . . . . . . . 38

a) Das mit Ear. Hik. $201 \mathrm{ff}$. verwandte Stuck . . . . . . . 38

b) Das mit Dio. Chrys. 3 gemeinsame Stack . . . . . . . 43

c) Die Verknapfung durch Xenophon. Weitere Einflasse des

Antisthenes? . . . . . . . . . . . . 46 
3. Xenophon und die Naturphilosophie; Angleichung an die eigene

Gottesvorstellung . . . . . . . . . . . . . . . . 49

4. Vorxenophontische Gedanken in Nem. 14 . . . . . . . . 51

\section{Anhang I}

Über Vergleich and piqnots bei den Vorsokratikern. . . . . . . . 54

Anhang II

Die Stoa und Diogenes von Apollonia . . . . . . . . . . . . . 57

Zweiter Tell: Plato

A. Der frahe Plato . . . . . . . . . . . . . . . . . . 62

1. Plato und die Naturphilosophie . . . . . . . . . . . 62

2. Die statische Seele . . . . . . . . . . . . . . . . 63

B. Der spatere Plato : . . . . . . . . . . . . . . . . 64

I. Allgemeines . . . . . . . . . . . . . . . . . . . . 64

1. Die Bewegangsseele des Phaidros . . . . . . . . . . . 64

2. Die Einfugung der Bewegung in das System Platos; die Auseinandersetzung mit Parmenides . . . . . . . . . . . 65

Parmenides und Platos Timaios . . . . . . . . . 68

3. Seele und Demiurg . . . . . . . . . . . . . . . . 69

Demiurg nicht Idee des Guten . . . . . . . . . . . 70

Ewigkeit der Welt . . . . . . . . . . . . . . . . 73

Kosmos und Idee . . . . . . . . . . . . . . . . 73

II. Spezielle Fragen der Teleologie . . . . . . . . . . . . . 74

Technikvergleiche . . . . . . . . . . . . . . . . . 75

Diogenes von Apollonia bei Plato?. . . . . . . . . . . 76

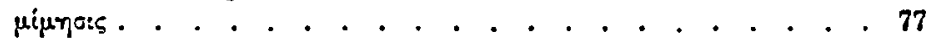

Anhang

Der Mythus des Politikos . . . . . . . . . . . . . . . . . 78

\section{Dritter Tell: Aristoteles}

A. Aristoteles im Dialog $\pi$ a ! çinoonquas . . . . . . . . . 83

B. Der spatere Aristoteles . . . . . . . . . . . . . . . 84

I. Die nene fócts-Auffassung . . . . . . . . . . . . . . . 84

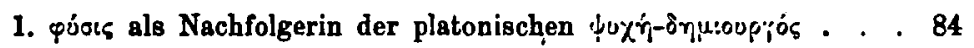

a) Grundsatzliche Ähnlichkeit zn Plato . . . . . . . . . 85

b) Die neue Auffassung schon im Protreptikos . . . . . . 86

c) Einzelne Beispiele fur das Fortwirken platonischer Ausdrucksweise . . . . . . . . . . . . . . . . . . . 89

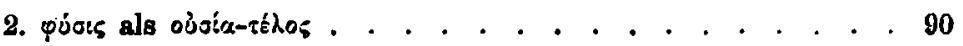

3. Verschmelzung von Bewegungsprinzip und हlìos . . . . . . 91

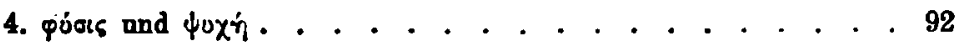

5. Die Darchbrechung der ب̣́s:s im Makro- und Mikrokosmos . . 93 
II. Teleologisuhe Fragen 10 Beite

1. Theologise Fragen. $\cdot \cdot \cdot \cdot \cdot \cdot \cdot \cdot \cdot \cdot \cdot \cdot \cdot \cdot \cdot \cdot 95$

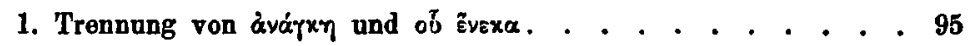

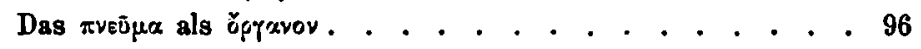

Die Ewigkeit des Werdens . . . . . . . . . . . 97

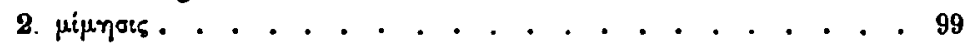

3. Das ei $i \delta s$ in der organischen Welt. . . . . . . . . . . 99

4. Fortfahrang fruherer Gedanken und Ausdracksweise . . . . 100

AbsehluB . . . . . . . . . . . . . . . . . . 102

1. Peripatos . . . . . . . . . . . . . 102

2. Ärzte . . . . . . . . . . . . . . . 108

3. Stoa . . . . . . . . . . . . . . . . 104

Index . . . . . . . . . . . . . . . . . . . . . . . . 105 